\title{
Sugar content and expression of sugar metabolism-related gene in strawberry fruits from various cultivars
}

\author{
Jeongyeo Lee $\cdot$ Hyun-Bi Kim $\cdot$ Young-Hee Noh $\cdot$ Sung Ran Min $\cdot$ Haeng-Soon Lee $\cdot$ Jaeeun Jung \\ Kun-Hyang Park • Dae-Soo Kim $\cdot$ Myeong Hyeon Nam $\cdot$ Tae Il Kim $\cdot$ Sun-Ju Kim $\cdot$ HyeRan Kim
}

Received: 28 May 2018 / Revised: 11 June 2018 / Accepted: 11 June 2018

(C) Korean Society for Plant Biotechnology

\begin{abstract}
Strawberry $($ Fragaria $\times$ ananassa $)$ is a globallycultivated and popular fruit crop, prized for its flavor and nutritional value. Sweetness, a key determinant of fruit quality, depends on the sugar composition and concentration. We selected eight strawberry cultivars based on the fruit soluble solids content to represent high and low sugar content groups. The average soluble solid content was $13.6^{\circ} \mathrm{Brix}$ (Okmae, Geumsil, Aram, and Maehyang) and $2.9^{\circ}$ Brix (Missionary, Camino Real, Portola, and Gilgyung53), for the high and low sugar content groups, respectively. Sucrose was the main sugar in the cultivars with high sugar content, whereas fructose was the main component in the low sugar content cultivars. Fruit starch concentration ranged from $3.247 \pm 0.056$ to $3.850 \pm 0.055 \mathrm{~g} / 100 \mathrm{~g}$, with a $12 \%$ higher concentration in the high sugar content cultivars. Additionally, we identified 41 sugar metabolism-related genes in Fragaria $\times$ ananassa and analyzed the relationship between their transcripts and the sugar accumulation in fruit. FaGPT1, FaTMT1, FaHXK1, FaPHS1, FaINVA-3, and FacxINV2-1 were highly expressed in the high sugar content cultivars, while FapGlcT, FaTMT2-1, FaPHS2-1, FaSUSY1-1, and FaSUSY1-2 were highly expressed in the low sugar content cultivars. In general, a greater number of genes encoding
\end{abstract}

J. Lee $\cdot$ H.-B. Kim $\cdot$ Y.-H. Noh · S. R. Min - H.-S. Lee · J. Jung $\cdot$ K.-H. Park $\cdot$ D.-S. Kim $\cdot$ H. Kim $(\bowtie)$

Korea Research Institute of Bioscience and Biotechnology, 125 Gwahak-ro, Yuseong-gu, Daejeon 34141, Republic of Korea

e-mail: hrkim@kribb.re.kr

M. H. Nam • T. I. Kim

Nonsan Strawberry Experiment Station, Chungcheong Nam- Do Agricultural Research and Extension Services, Nonsan-si,

Chungnam-do, 32914, Republic of Korea

\section{S.-J. Kim $(\bowtie)$}

Department of Bio-Environmental Chemistry, Chungnam National University, Daejeon 34134, Republic of Korea e-mail: kimsunju@cnu.ac.kr sugar transporters or involved in sugar synthesis were highly expressed in the high sugar content cultivars. Contrarily, genes involved in sugar degradation were preferentially transcribed in the low sugar content cultivars. Although gene expression was not perfectly proportional to sugar content or concentration, our analysis of the genes involved in sugar metabolism and accumulation in strawberries provides a framework for further studies and for the subsequent engineering of sugar metabolism to enhance fruit quality.

Keywords Soluble sugar, Glucose, Fructose, Sucrose, Fragaria $\times$ ananassa

\section{Introduction}

Strawberry (Fragaria $\times$ ananassa) is one of the most popular and widely-consumed fruits worldwide. In strawberry production, sweetness, flavor, color, and juiciness are important traits, because they affect consumer and industrial demand. The relationship between sugars and sensory properties, such as flavor or color has been under study for a long time (Alavoine and Crochon 1989; Wozniak et al. 1997). Sweetness is one of the most desirable characteristics in commercially grown strawberries, and is influenced by the amount and composition of sugars accumulated in the fruit (Basson et al. 2010). This quality is primarily determined genetically and environmentally (Kallio et al. 2000; Wang and Camp 2000; Pelayo-Zaldivar et al. 2005; Gündüz and Özdemir 2014). Sugars and the organic acids present in the fruit determine the overall fruit flavor (Kallio et al. 2000; Park et al. 2006). Additionally, sugar content is also dependent on total solids, $\mathrm{pH}$, acidity, and fruit size; furthermore, sugar composition varies with fruit ripeness (Reyes et al. 1982).

Glucose, fructose, and sucrose are the main soluble sugars 
accumulated in strawberry fruits (Woodward 1972; Ranwala et al. 1992). These soluble sugars account for approximately $99 \%$ of the total fruit sugar content; furthermore, the soluble sugar content significantly increases during fruit development (Makinen and Söderling 1980; Jia et al. 2013). Glucose and fructose concentrations are higher during growth than in the ripe fruits (Forney and Breen 1986), although the amounts of glucose, fructose, and sucrose vary with the degree of ripeness (Kafkas et al. 2007). Several studies have shown qualitative and quantitative variations in the composition of soluble sugars in strawberry cultivars (Basson et al. 2010; Gündüz and Özdemir 2014). Understanding the factors that control carbohydrate partitioning is necessary for improving the efficiency of metabolic engineering. Till date, we do not have enough information on the molecular mechanisms responsible for the control of soluble sugar concentration in strawberries. Until now, molecular approaches have focused on specific sugar-metabolism pathways regulated during ripening (Park et al. 2006), and activities of only some enzymes have been measured, such as sucrose synthase, neutral- and soluble acid invertase, etc. (Hubbard et al. 1991; Ranwala et al. 1992). Nevertheless, the difference in soluble sugar content among different strawberry cultivars remains unclarified.

In this study, we aimed to elucidate the relationship between sugar concentration and gene expression in fully ripened strawberries by analyzing sugar content and sugar concentration in selected strawberry cultivars, which have either a low or high sugar level. We also examined the expression patterns of sugar metabolism-related genes, such as those involved in sugar transport, sugar synthesis, and sugar degradation. The findings of this study may facilitate the future selection of molecular genetic targets to improve carbohydrate accumulation in strawberries.

\section{Materials and Methods}

Plant materials

Strawberries were grown in a greenhouse at Chungnam Agricultural Research and Extension in South Korea, from November, 2016 to April, 2017. Cultivars included Missionary, Camino Real, Portola, Gilgyung53, Okmae, Geumsil, Aram, and Maehyang. All fruit samples were collected at maturity and freeze-dried by storing at $-55^{\circ} \mathrm{C}$. Freeze-dried samples were then stored at $4^{\circ} \mathrm{C}$ until use for HPLC-ELSD analysis and total RNA isolation.
Preparation of soluble sugars and starch extracts

Sugar content of all cultivars were measured using fresh fruit samples with a Digital Refractometer GMK-703AC (G-won hightech, Korea). Approximately $0.2 \mathrm{~g}$ of freezedried fruit tissue was dissolved in $20 \mathrm{ml}$ of ethanol (80\%) with vigorous stirring for $20 \mathrm{~min}$, followed by sonication for $10 \mathrm{~min}$ and further stirring for $5 \mathrm{~min}$. The resulting mixture was centrifuged at $3,000 \mathrm{rpm}$ for $10 \mathrm{~min}$ at $4^{\circ} \mathrm{C}$, as described by Shanmugavelan et al. (2013). The supernatant solution was filtered through a $0.45-\mu \mathrm{m}$ filter and used for sugar analysis by HPLC-ELSD. Following ethanol extraction, tissue pellets were re-suspended in $8 \mathrm{ml}$ of sterile distilled water and starch was gelatinized in a water bath at $100^{\circ} \mathrm{C}$ for $1 \mathrm{~h}$. Gelatinized starch was converted to glucose by the addition of $2 \mathrm{ml} 0.5 \mathrm{M}$ sodium acetate buffer $(\mathrm{pH}$ 5.2) containing 10 units of amyloglucosidase (Roche Molecular Biochemicals, UK). Samples were incubated at $37^{\circ} \mathrm{C}$ overnight and then centrifuged at 13,000 g for $5 \mathrm{~min}$. Glucose released from starch was determined by HPLC-ELSD (Souleyre et al. 2004).

\section{HPLC-ELSD analysis}

Analysis of sugars by HPLC was performed isocratically using a carbohydrate column ( $\mathrm{S} 5 \mu \mathrm{m}, 250 \mathrm{~mm} \times 4.6 \mathrm{~mm}$ i.d) using the following HPLC conditions: flow rate $=1.0 \mu \mathrm{l} / \mathrm{min}$, data rate $=1 \mathrm{pps}$, run time $=15 \mathrm{~min}$, gain $=1$, column heater temperature $=35^{\circ} \mathrm{C}$, sample temperature $=5^{\circ} \mathrm{C}$, pressure $=$ 50 psi, Nebulizer: heating $(90 \%)$ and injection volume $=$ $10 \mu \mathrm{l}$. An acetonitrile:water (7:3) mixture was used as the mobile phase, as described by Shanmugavelan et al. (2013). For quantification and calibration, a standard solution mixture was prepared by dissolving $\mathrm{D}(+)$ fructose, $\mathrm{D}(+)$ glucose, and $\mathrm{D}(+)$ sucrose in water (HPLC grade) to attain the following five different concentrations: 50, 100, 500, 1,000, 2,500, and 5,000 ppm.

Candidate gene identification of sugar metabolism

The sugar-related genes of Arabidopsis thaliana were searched from NCBI GenBank (https://www.ncbi.nlm.nih.gov/). Collected genes were subjected to a tBlastN search against our internal transcriptome database of Fragaria $\times$ ananassa (unpublished data) and GDR database (https://www.rosaceae.org/) to identify their homologues in the strawberry genome. Only resultant sequences with e-value of $<1 \mathrm{e}^{-100}$ and identity of $>30 \%$ were considered as orthologous genes. In all, 41 Fragaria $\times$ ananassa sugar metabolism-related genes were selected; 
Table 1 Soluble solid contents and composition of sugars (g/100 g) of selected strawberry cultivars. Values (mean \pm SD) are average of duplicate samples analyzed individually in triplicate for sugar concentration

\begin{tabular}{lcccccc}
\hline & \multirow{2}{*}{$\begin{array}{c}\text { Soluble solid contents } \\
\left({ }^{\circ} \text { Brix }\right)\end{array}$} & \multicolumn{2}{c}{ Sugar concentration $(\mathrm{g} / 100 \mathrm{~g})$} & \multicolumn{2}{c}{$\begin{array}{c}\text { Starch } \\
(\mathrm{g} / 100 \mathrm{~g})\end{array}$} \\
\cline { 3 - 6 } & $2.3 \pm 0.3$ & $1.027 \pm 0.006$ & $2.461 \pm 0.007$ & $0.628 \pm 0.011$ & $4.116 \pm 0.009$ & $3.268 \pm 0.088$ \\
Missionary & $3.5 \pm 0.1$ & $1.460 \pm 0.006$ & $2.799 \pm 0.011$ & $0.535 \pm 0.005$ & $4.794 \pm 0.007$ & $3.247 \pm 0.056$ \\
Camino Real & $2.7 \pm 0.3$ & $1.404 \pm 0.003$ & $2.623 \pm 0.007$ & $0.437 \pm 0.005$ & $4.464 \pm 0.004$ & $3.357 \pm 0.061$ \\
Portola & $3.1 \pm 0.1$ & $1.481 \pm 0.005$ & $2.754 \pm 0.010$ & $0.352 \pm 0.003$ & $4.587 \pm 0.007$ & $3.457 \pm 0.079$ \\
Gilgyung53 & $14.3 \pm 0.6$ & $2.742 \pm 0.005$ & $3.056 \pm 0.006$ & $6.294 \pm 0.032$ & $12.092 \pm 0.016$ & $3.794 \pm 0.132$ \\
Geumsil & $13.9 \pm 0.7$ & $3.079 \pm 0.006$ & $4.802 \pm 0.011$ & $7.571 \pm 0.021$ & $15.452 \pm 0.013$ & $3.850 \pm 0.055$ \\
Aram & $13.6 \pm 0.6$ & $1.331 \pm 0.001$ & $2.236 \pm 0.001$ & $4.503 \pm 0.007$ & $8.070 \pm 0.004$ & $3.725 \pm 0.051$ \\
Maehyang & $13.6 \pm 0.8$ & $1.687 \pm 0.006$ & $2.236 \pm 0.010$ & $4.399 \pm 0.017$ & $8.322 \pm 0.011$ & $3.615 \pm 0.077$ \\
Okmae & & & & & &
\end{tabular}

the gene-specific primers were designed with Primer3 (v. 0.4.0) (http://bioinfo.ut.ee/primer3-0.4.0/primer3/) and used for RT-PCR analysis. The accession numbers of the genes and primer sets used in this study are listed in Table 2 and Supplementary Table 1, respectively.

\section{RNA extraction and RT-PCR analysis}

Reverse transcription-polymerase chain reaction was used to analyze the expression of genes involved in sugar metabolism. Total RNA was prepared from freeze-dried fruit samples following the methods of Yu et al. (2012) using an extraction buffer containing 3\% CTAB, $100 \mathrm{mM}$ Tris- $\mathrm{HCl}$ (pH 8.0), 1.4 M NaCl, $20 \mathrm{mM}$ EDTA, 5\% PVP, and 1\% $\beta$-mercaptoethanol. First-strand cDNA was synthesized from $1 \mu \mathrm{g}$ isolated total RNA using the ReverTra Ace- $\alpha$ cDNA synthesis kit (TOYOBO, Japan) following the manufacturer's protocol; RT-PCR was performed using the primers listed in Supplementary Table 1.

\section{Results and Discussion}

Soluble solid and sugar content analysis in strawberry cultivars

Strawberry (Fragaria $\times$ ananassa) is a globally cultivated and consumed fruit crop valued for its flavor and abundant nutrition. Sweetness is one of the most important quality of strawberry that determines the preference of consumers and industry (Sturm et al., 2003; Gündüz and Özdemir, 2014). Eight strawberry cultivars were selected on the basis of fruit soluble-solids content ( $\left.{ }^{\circ} \mathrm{Brix}\right)$ as representative of low- and high-sugar groups among 60 different strawberry cultivars. The average values were 13.6 and $2.9^{\circ}$ Brix for high and low sugar-content cultivars, respectively (Table 1). The high sugar-content cultivars included Okmae (13.6 $\pm 0.8^{\circ}$ Brix $)$, Geumsil (14.3 $\pm 0.6^{\circ}$ Brix), Aram (13.9 $\pm 0.7^{\circ}$ Brix), and Maehyang (13.6 $\pm 0.6^{\circ}$ Brix), while the low sugar-content cultivars were Missionary (2.3 $\pm 0.3{ }^{\circ}$ Brix), Camino Real (3.5 $\pm 0.1^{\circ}$ Brix), Portola (2.7 $\pm 0.3^{\circ}$ Brix $)$, and Gilgyung53 $\left(3.1 \pm 0.1{ }^{\circ}\right.$ Brix).

Sugar content measured in fruits of all these cultivars are compared in Table 1. Total soluble sugar content in the high sugar-content cultivars was 2.45 times higher than that in the low sugar-content cultivars. It is noteworthy that, among the sugars analyzed here, sucrose showed the most significant difference in concentration between the highand low sugar-content cultivars. Sucrose content was the highest among that of all the soluble sugars present in the fruits of the high sugar-content cultivars, ranging between $4.399 \pm 0.017$ and $7.571 \pm 0.021 \mathrm{~g} / 100 \mathrm{~g}$, while glucose content was the lowest, ranging from $1.331 \pm 0.001$ to $3.079 \pm$ $0.006 \mathrm{~g} / 100 \mathrm{~g}$ (Table 1). Sugar content and the ratio of soluble sugar concentration in the high sugar-content cultivars showed a similar trend to that previously reported for the cultivars Maehyang, Seolhyang, Festival, and Sweet Charlie (Shanmugam et al. 2017). In the case of the low sugarcontent cultivars, fructose content was the highest (2.461 \pm $0.007 \mathrm{~g} / 100 \mathrm{~g}-2.799 \pm 0.011 \mathrm{~g} / 100 \mathrm{~g})$, while sucrose content was the lowest $(0.352 \pm 0.003 \mathrm{~g} / 100 \mathrm{~g}-0.628 \pm 0.011 \mathrm{~g} / 100 \mathrm{~g})$ among all the soluble sugars quantitated (Table 1). It has been reported that fructose and glucose are the main sugars in strawberries from the analysis of Festival, Sweet Charlie, Camaraso, Selva, and 12 other cultivars mainly grown in the USA and Europe. (Castro et al. 2002; Sturm et al. 2003; Shanmugam et al. 2017). In this study, two contrasting groups of cultivars differed in their respective sugar composition; sucrose was the main sugar present in the high sugar-content cultivars, while fructose prevailed 

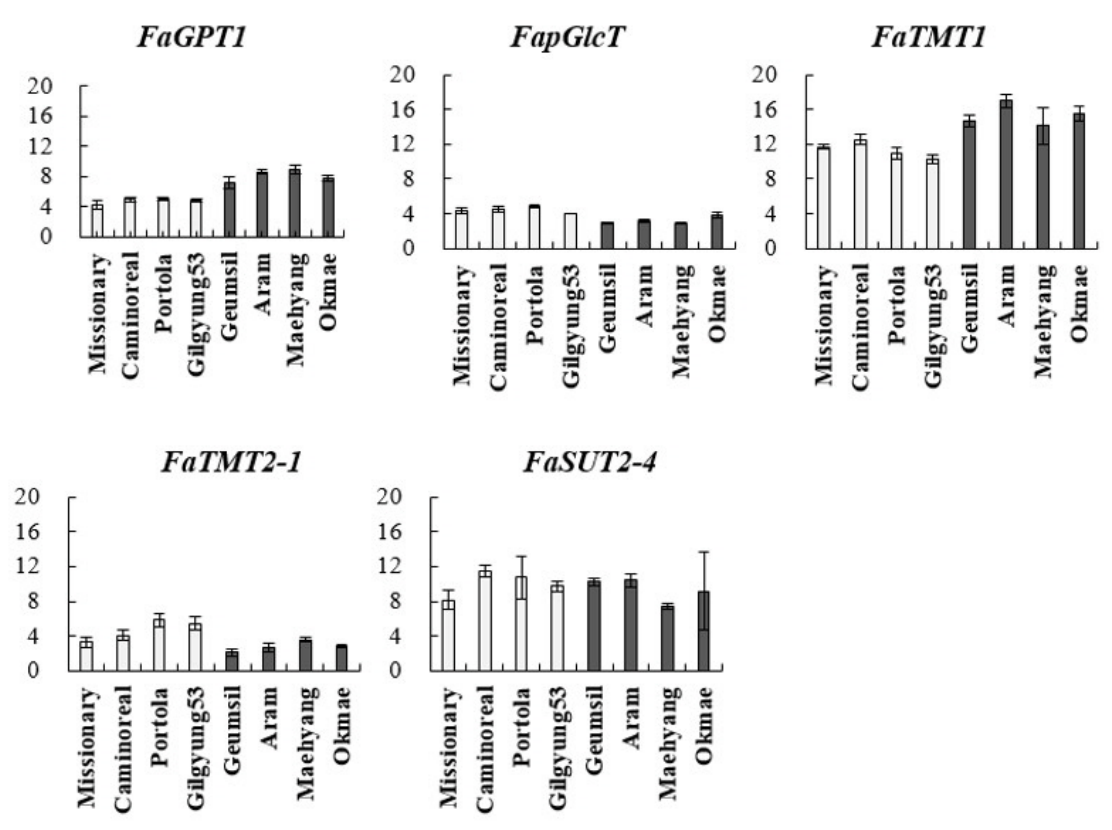

Fig. 1 Relative mRNA expression of putative genes involved in sugar transportation. RT-PCR analysis of different members of the sugar transporter genes in high (gray bar) and low sugar content cultivars (white bar). RNA levels were quantified and normalized to the level of $F a G A P D H$. Values are means $\pm \mathrm{SD}$ of three samples

in the low sugar-content cultivars. Fruit starch concentration in the eight cultivars examined ranged from $3.247 \pm 0.056$ contained $12 \%$ more starch than the low sugar-content cultivars (Table 1). It has been reported that starch accumulates at the early stages of strawberry maturation and is rapidly degraded as fruits ripen (Souleyre et al. 2004). Our results demonstrated that the extent of starch accumulation, or conversely, the extent of starch degradation in the cultivars under study were different and contributed to the differences recorded in the starch and sugar content among the two groups of cultivars studied.

Identification of sugar metabolism-related genes in Fragaria $\times$ ananassa

Sugar metabolism and accumulation pathways have been extensively characterized in plants (Supplementary Fig. 1). Here we focused on searching genes related with the utilization and transport of the three major sugars quantitated in this study (Table 1). To identify putative sugarmetabolism genes in Fragaria $\times$ ananassa, 26 mRNA sequences related to sugar metabolism were collected as a reference from the Arabidopsis genome (Rolland et al. 2006). We obtained a total of 41 transcripts including, 11 sugar transporter genes, 4 hexose-related genes, 9 sucrosesynthesis genes, and 17 sucrose-degradation genes (Table 2). Multiple copies of transcripts were detected for FaINVG (invertase G), FaINVA (invertase A), FacwINV2 (cell wall invertase 2), FacwINV5, FaPHS2 (alpha-glucan phosphorylase 2), FaSUT2 (sucrose transporter 2), FaSUSY1 (sucrose synthase 1), FaSUSY2 (sucrose synthase 2), and FaTMT2 (tonoplast monosaccharide transporter 2), suggesting that Fragaria $\times$ ananassa uses multiple isoforms of these sugar metabolismrelated genes, either in a spatial or in a developmental-stage specific manner (Supplementary Fig. 2).

Expression profiling of sugar metabolism-related genes in Fragaria $\times$ ananassa

Aiming to elucidate the expression patterns of sugar metabolism-related genes, we carried out semi-quantitative RT-PCR for sugar transporters, hexose-related genes, sucrose synthesis genes, and sucrose-degradation genes in the two groups of strawberry cultivars identified on the basis of sugar content (Figs. 1-4, Supplementary Fig. 2). Among the 11 sugar-transporter genes, only FaGPTl (glucose 6-phosphate/phosphate translocator 1), FapGlcT (plastidic glucose translocator), FaTMT1, FaTMT2-1, and FaSUT2-4 were expressed in mature strawberries (Fig. 1). The expression of FaGPT1 and FaTMT1 were 1.70-fold and 1.35-fold greater, respectively, in the high sugar-content cultivars than in the low sugar-content cultivars. In contrast, the expression of FapGlcT and FaTMT2-1 were 1.39-fold and 1.66-fold greater, respectively in the low sugar-content cultivars. On the contrary, FaTMT2-2, FaSUT2-1 and FaSUT2-3 were not expressed in either fruit type (Supplementary Fig. 2). Based on the 
Table 2 Sugar metabolism related genes identified in Fragaria $\times$ ananassa

\begin{tabular}{|c|c|c|c|c|c|c|c|c|}
\hline \multirow[b]{2}{*}{ Function } & \multicolumn{3}{|c|}{ Arabidopsis thaliana } & \multicolumn{3}{|c|}{ Fragaria $\times$ ananassa } & \multirow[b]{2}{*}{$\begin{array}{c}\text { Identity } \\
(\%)\end{array}$} & \multirow[b]{2}{*}{ E-value } \\
\hline & Gene name & Locus ID & $\begin{array}{c}\text { CDS length } \\
\text { (bp) }\end{array}$ & Gene name & Gene ID & $\begin{array}{l}\text { CDS length } \\
\text { (bp) }\end{array}$ & & \\
\hline \multirow{11}{*}{$\begin{array}{l}\text { Sugar } \\
\text { transporter }\end{array}$} & $A t G P T 1$ & At5g54800 & 1,176 & FaGPT1 & mrna03202.1-v1.0-hybrid & 392 & 100 & 0 \\
\hline & AtpGlcT & At5g16150 & 1,599 & FapGlcT & mrna12375.1-v1.0-hybrid & 533 & 100 & 0 \\
\hline & AtTMT1 & At1g20840 & 1,959 & FaTMT1 & mrna31477.1-v1.0-hybrid & 653 & 100 & 0 \\
\hline & AtTMT2 & At4g35300 & 2,394 & FaTMT2-1 & mrna17337.1-v1.0-hybrid & 798 & 100 & 0 \\
\hline & & & & FaTMT2-2 & mrna13020.1-v1.0-hybrid & 803 & 60.4 & 0 \\
\hline & AtSUC2 & At1g22710 & 1,515 & FaSUT2-1 & mrna27493.1-v1.0-hybrid & 505 & 100 & 0 \\
\hline & & & & FaSUT2-2 & mrna15110.1-v1.0-hybrid & 497 & 73.5 & 0 \\
\hline & & & & FaSUT2-3 & mrna08189.1-v1.0-hybrid & 499 & 71.3 & 0 \\
\hline & & & & FaSUT2-4 & mrna32070.1-v1.0-hybrid & 492 & 70.4 & 0 \\
\hline & & & & FaSUT2-5 & mrna15111.1-v1.0-hybrid & 493 & 69.4 & 0 \\
\hline & AtSUC4 & At1g09960 & 1,821 & FaSUT4 & mrna26850.1-v1.0-hybrid & 607 & 100 & 0 \\
\hline \multirow{4}{*}{$\begin{array}{l}\text { Hexose- } \\
\text { related }\end{array}$} & AtHXK1 & At4g29130 & 1,449 & $\mathrm{FaHXK1}$ & mrna25718.1-v1.0-hybrid & 483 & 100 & 0 \\
\hline & AtHXK2 & At2g19860 & 1,497 & FaHXK2 & mrna11313.1-v1.0-hybrid & 499 & 100 & 0 \\
\hline & $A t P G I$ & At4g24620 & 1,872 & FaPGI & mrna12096.1-v1.0-hybrid & 624 & 100 & 0 \\
\hline & $A t P G M$ & At5g51820 & 1,854 & FaPGM & mrna13359.1-v1.0-hybrid & 618 & 100 & 0 \\
\hline \multirow{9}{*}{$\begin{array}{l}\text { Sucrose- } \\
\text { synthesis }\end{array}$} & AtPHS1 & At3g29320 & 3,045 & FaPHSI & mrna04322.1-v1.0-hybrid & 1,015 & 100 & 0 \\
\hline & AtPHS2 & At3g46970 & 2,508 & FaPHS2-1 & mrna07968.1-v1.0-hybrid & 836 & 100 & 0 \\
\hline & & & & FaPHS2-2 & mrna29749.1-v1.0-hybrid & 1,010 & 50.1 & 0 \\
\hline & AtSPP1 & At1g51420 & 1,806 & FaSPP1 & mrna18142.1-v1.0-hybrid & 602 & 100 & 0 \\
\hline & $A t S P P 4(3 b)$ & At3g52340 & 366 & FaSPP4 & mrna30374.1-v1.0-hybrid & 122 & 100 & $1.56 \mathrm{E}-19$ \\
\hline & AtSPSA1 & At5g20280 & 3,189 & FaSPSA1 & mrna31122.1-v1.0-hybrid & 1,063 & 100 & 0 \\
\hline & AtSPSA2 & At5g11110 & 3,174 & FaSPSA2 & mrna1 1606.1-v1.0-hybrid & 1,058 & 100 & 0 \\
\hline & AtSPSB & At1g04920 & 3,201 & FaSPSB & mrna06523.1-v1.0-hybrid & 1,067 & 100 & 0 \\
\hline & AtSPSC & At4g10120 & 3,081 & FaSPSC & mrna31164.1-v1.0-hybrid & 1,027 & 100 & 0 \\
\hline \multirow{17}{*}{$\begin{array}{l}\text { Sucrose- } \\
\text { degradation }\end{array}$} & AtSUSY1 & At5g20830 & 2,421 & FaSUSY1-1 & mrna12940.1-v1.0-hybrid & 807 & 100 & 0 \\
\hline & & & & FaSUSY1-2 & mrna11429.1-v1.0-hybrid & 1,526 & 82.8 & 0 \\
\hline & AtSUSY2 & At5g49190 & 2,364 & FaSUSY2-1 & mrna07050.1-v1.0-hybrid & 788 & 100 & 0 \\
\hline & & & & FaSUSY2-2 & mrna31666.1-v1.0-hybrid & 825 & 55.6 & 0 \\
\hline & AtSUSY3 & At4g02280 & 2,544 & FaSUSY3 & mrna11077.1-v1.0-hybrid & 848 & 100 & 0 \\
\hline & AtSUSY5 & At5g37180 & 5,871 & FaSUSY5 & mrna09290.1-v1.0-hybrid & 1,957 & 100 & 0 \\
\hline & $A / N-I N V-G$ & At1g35580 & 1,659 & FaINVG-1 & mrna07792.1-v1.0-hybrid & 553 & 100 & 0 \\
\hline & & & & FaINVG-2 & mrna07379.1-v1.0-hybrid & 718 & 78.9 & 0 \\
\hline & & & & FaINVG-3 & mrna08524.1-v1.0-hybrid & 602 & 76.2 & 0 \\
\hline & & & & FaINVG-4 & mrna18695.1-v1.0-hybrid & 583 & 71.1 & 0 \\
\hline & $A / N-I N V-A$ & At1g56560 & 1,962 & FaINVA-1 & mrna00239.1-v1.0-hybrid & 654 & 100 & 0 \\
\hline & & & & FaINVA-2 & mrna05019.1-v1.0-hybrid & 656 & 72.5 & 0 \\
\hline & & & & FaINVA-3 & mrna22002.1-v1.0-hybrid & 670 & 67 & 0 \\
\hline & AtcwINV2 & At3g52600 & 1,878 & FacwINV2-1 & mrna23034.1-v1.0-hybrid & 626 & 100 & 0 \\
\hline & & & & FacwINV2-2 & mrna15509.1-v1.0-hybrid & 572 & 56.1 & 0 \\
\hline & AtcwINV5 & At3g13784 & 1,533 & FacwINV5-1 & mrna06912.1-v1.0-hybrid & 511 & 100 & 0 \\
\hline & & & & FacwINV5-2 & mrna23031.1-v1.0-hybrid & 950 & 74.5 & 0 \\
\hline
\end{tabular}




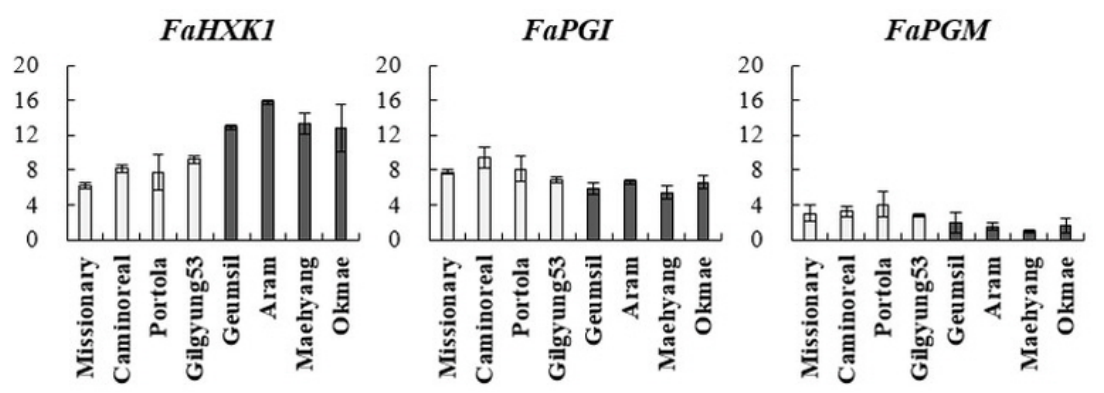

Fig. 2 Relative mRNA expression of hexose-related genes. RT-PCR analysis of different members of the sugar transporter genes in high (gray bar) and low sugar content cultivars (white bar). RNA levels were quantified and normalized to the level of FaGAPDH. Values are means $\pm \mathrm{SD}$ of three samples

expression patterns obtained, FaTMT1 seemed the main FaTMT sugar transporter gene in strawberry fruits. Further, FaSUT2-4 was the only sucrose transporter gene expressed in the fruits of all eight cultivars under study here, which showed a variable expression pattern in the different cultivars (Fig. 1). As for glucose translocator genes, the expression patterns of FaGPT1 and FapGlcT were mutually opposing, since they encode glucose transporters that transport glucose through the cytosol and chromoplast in opposite directions (Linka and Weber 2005), thereby playing an important role during chromoplast differentiation and fruit ripening by regulating glucose phosphate concentration in the fruit. With respect to sucrose transporters, they are localized in the plasma membrane (Butowt et al. 2003; Rolland et al. 2006; Fettke et al. 2009), indicating sucrose transport from the phloem in the source tissues to the cytosol of cells in the sink tissues; this is especially true for FaSUT2-4 in strawberries.

Our results revealed two genes regulating hexose conversion (FaPGI (phosphoglucoisomerase) and FaPGM (phosphoglucomutase)) and two more regulating hexose phosphorylation (FaHXK1 (hexokinase 1) and FaHXK2 ((hexokinase 2)) during sugar metabolism (Table 2). FaHXK2 was not expressed in mature strawberry fruits and the transcript level of FaHXK1 was 1.74-fold higher in the high sugarcontent cultivars (Fig. 2, Supplementary Fig. 2). The expression patterns of FaPGI and FaPGM showed no significant difference between the two groups of strawberry cultivars under study here (Fig. 2).

Among the 9 sucrose synthesis-related genes, FaPHS1 (alpha glucan phosphorylase 1), FaPHS2-1 (alpha glucan phosphorylase 2-1), FaSPP1 (sucrose-phosphatase 1), and FaSPSA1 (sucrose phosphate synthase 1) were expressed in strawberry fruits (Supplementary Fig. 2). Transcript level of FaPHSl was 1.85 -fold higher in the high sugar-content cultivars, whereas FaPHS2-1 was 2.25-fold higher in the low sugar-content cultivars. FaSPP1 and FaSPSA1 showed similar patterns of expression in both groups of cultivars.
The expression of FaSPSAl was the lowest among the expression of all examined sucrose synthesis-related genes. Higher expression level was detected for FaPHS1 and FaSPP1 in the high sugar-content cultivars, and for FaPHS2-1 and FaSPP1 in the low sugar-content cultivars (Fig. 3).

In most plants, sucrose is the major carbohydrate imported from source tissues. There are two sources for sucrose accumulation: imported sucrose that has not been metabolized, and newly synthesized sucrose from hexoses (Butowt et al. 2003; Rolland et al. 2006; Fettke et al. 2009). The SPS and $S P P$ genes contribute to synthesizing sucrose in the cytosol, while $P H S$ provides substrate for sucrose synthesis by cleaving glycosidic bonds of heteroglycans in the cytosol (Fettke et al. 2009). In this study, FaPHS1 showed the clearest difference in expression level between the two groups of cultivars, with the higher expression level in the high-sugar-content cultivars.

To compare the expression patterns of sugar metabolismrelated genes between our two groups of strawberry cultivars, we examined the transcript level of sucrose synthases (SUSYS) and invertases (INVs). Among the 6 SUSYs, only FaSUSY1-1 and FaSUSY1-2 were expressed in strawberry fruits (Supplementary Fig. 2), with 2.45-fold and 1.41-fold, higher levels, respectively, in the low sugar-content cultivars. FaSUSY1-2 seemed to be the major sugar synthase gene among the 6 homologs examined. Additionally, expression level of FaSUSY1-1 was low only in Geumsil and Aram, which accumulated large quantities of hexoses (Fig. 4). As for invertases, FaINVG-1, FaINVA-1, FaINVA-2, FaINVA-3, and FacwINV2-1 were expressed in strawberry fruits; FaINVG-1 was considered as major gene for sucrose degradation in Fragaria $\times$ ananassa, based on the high transcriptional level expressed in all cultivars, whereas other invertases were only slightly expressed in strawberry fruits with similar levels in both, the high- and low sugar-content cultivars. The expression levels of FaINVA-3 and FacwINV2-1 were particularly higher in the high sugar-content cultivars 

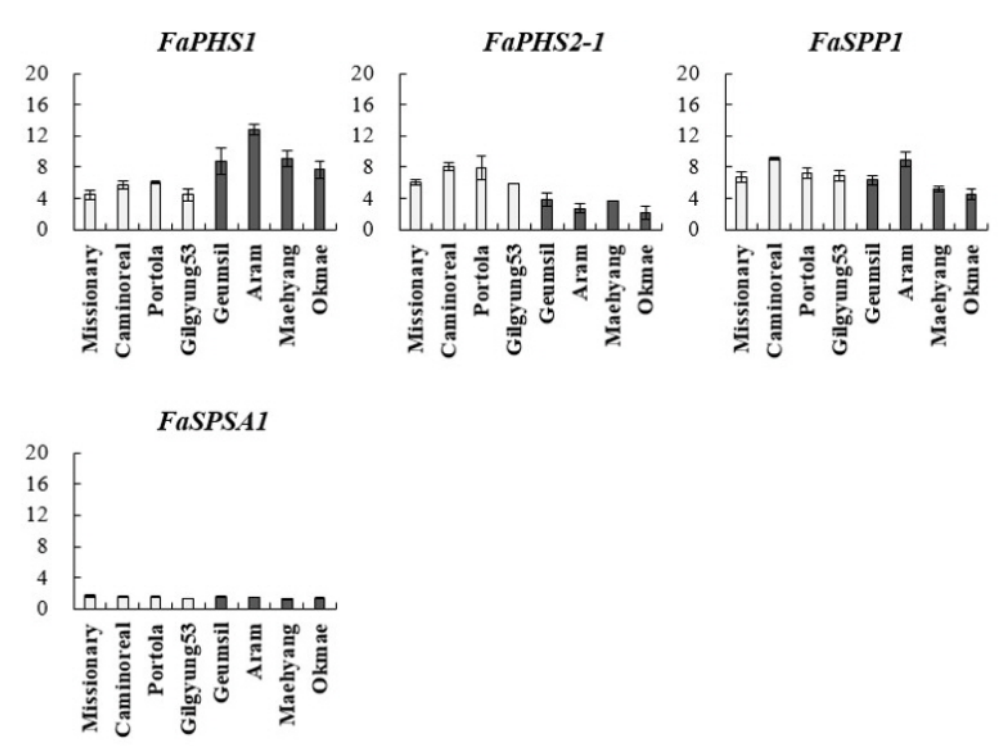

Fig. 3 Relative mRNA expression of sucrose synthesis genes. RT-PCR analysis of different members of the sugar transporter genes in high (gray bar) and low sugar content cultivars (white bar). RNA levels were quantified and normalized to the level of FaGAPDH. Values are means $\pm \mathrm{SD}$ of three samples
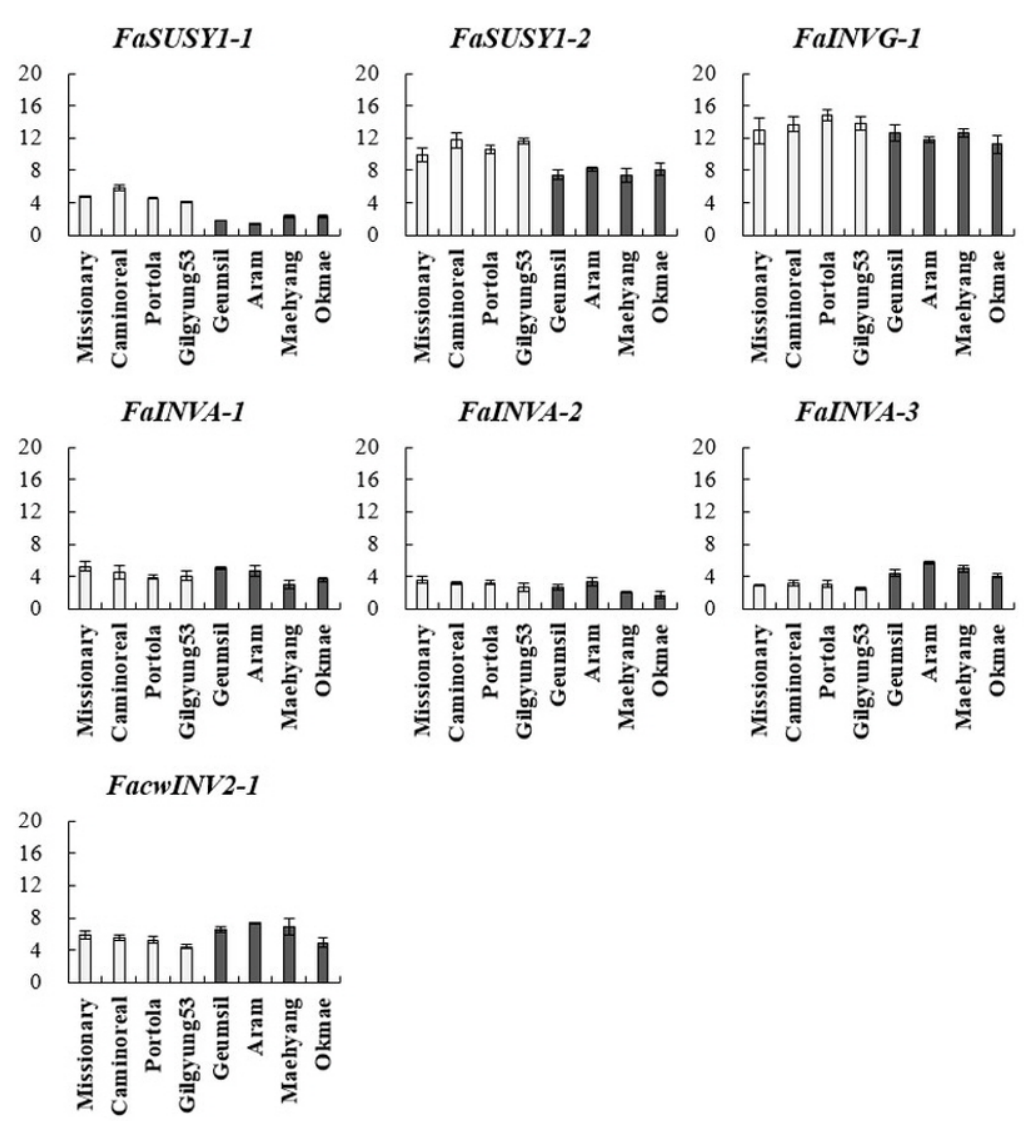

Fig. 4 Relative mRNA expression of putative genes involved in sucrose-degradation. RT-PCR analysis of different members of the sugar metabolism genes in high (gray bar) and low sugar content cultivars (white bar). RNA levels were quantified and normalized to the level of FaGAPDH. Values are means $\pm \mathrm{SD}$ of three samples

(Fig. 4). The concentration and composition of sugars in plant cells are modulated by sugar metabolism. Mainly glucose, fructose, and sucrose are affected by both internal and external factors, such as developmental processes and environmental conditions (Ruan et al. 2010; Dai et al. 2011). Among the various sugars present in strawberry fruits of 
the cultivars analyzed in this study, sucrose dominated the sugar profile; thus, genes involved in sucrose metabolism should be considered important candidate genes for application in developing high sugar-content cultivars (Jia et al. 2013; Jia et al. 2016). Sucrose synthase activity was relatively high in the early stages of ripening, but decreased as ripening progressed. Similarly, neutral and soluble acid invertase activities decreased during ripening (Hubbard et al. 1991; Souleyre et al. 2004; Basson et al. 2010). However, some reports have shown that soluble acid invertase activity increased with fruit ripening, which correlated with an increase of glucose and fructose (Ranwala et al. 1992).

\section{Conclusion}

In this study, we investigated the relationship between sugar content, sugar concentration, and sugar metabolism-related gene expression by comparing the low- and high sugarcontent cultivars in terms of these variables. We measured total soluble sugar concentration, which was proportional to sugar content in strawberry fruits. Among glucose, fructose, and sucrose, sucrose markedly influenced the sweetness of strawberry fruits. Further, sucrose was responsible for the largest difference between the two groups of cultivars under study. From gene expression profiling of sugar metabolism, we found several sugar-related genes, such as FaGPT1, FaTMT1, FaHXK1, FaPHS1, FaINVA-3, and FacwINV2-1, which were highly expressed in the high sugar-content cultivars, suggesting they may play important roles in controlling the accumulation of sugar in strawberry fruits. This work represents a comprehensive analysis of genes involved in sugar metabolism and accumulation in strawberry fruits; our data on their expression profile in ripening strawberry fruits will be helpful for further manipulation and application in the development of controlled sugar content cultivars for research and commercial purposes.

\section{Acknowledgement}

This work was supported by grants from the export promotion technology development research programs (315047-3) funded by the Ministry of Agriculture, Food and Rural Affairs, Republic of Korea, and a grant from the KRIBB Research Initiative Program.

\section{References}

Alavoine F, Crochon M (1989) Taste quality of strawberry. Acta
Hortic 265:449-452

Basson CE, Groenewald JH, Kossmann J, Cronjé C, Bauer R (2010) Sugar and acid-related quality attributes and enzyme activities in strawberry fruits: Invertase is the main sucrose hydrolysing enzyme. Food Chem 121:1156-1162

Butowt R, Granot D, Rodríguez-García MI (2003) A putative plastidic glucose translocator is expressed in heterotrophic tissues that do not contain starch, during olive (Olea europea L.) fruit ripening. Plant Cell Physiol 44:1152-1161

Castro I, Goncalves O, Teixeira JA, Vicente AA (2002) Comparative study of Selva and Camarosa strawberries for the commercial market. J Food Sci 67:2132-2137

Dai N, Cohen S, Portnoy V, Tzuri G, Harel-Beja R, Pompan-Lotan M, Carmi N, Zhang G, Diber A, Pollock S, Karchi H, Yeselson Y, Petreikov M, Shen S, Sahar U, Hovav R, Lewinsohn E, Tadmor Y, Granot D, Ophir R, Sherman A, Fei Z, Giovannoni J, Burger Y, Katzir N, Schaffer AA (2011) Metabolism of soluble sugars in developing melon fruit: A global transcriptional view of the metabolic transition to sucrose accumulation. Plant Mol Biol 76:1-18

Fettke J, Malinova I, Eckermann N, Steup M (2009) Cytosolic heteroglycans in photoautotrophic and in heterotrophic plant cells. Phytochemistry 70:696-702

Forney CF, Breen PJ (1986) Sugar content and uptake in strawberry fruit. J Am Soc Hortic Sci, 111:241-247

Gündüz K, Özdemir E (2014) The effects of genotype and growing conditions on antioxidant capacity, phenolic compounds, organic acid and individual sugars of strawberry. Food Chem 155: 298-303

Hubbard N, Pharr D, Huber S (1991) Sucrose phosphate synthase and other sucrose metabolising enzymes in fruits of various species. Physiol Plantarum 82:191-196

Jia H, Jiu S, Zhang C, Wang C, Tariq P, Liu Z, Wang B, Cui L, Fang $J$ (2016) Abscisic acid and sucrose regulate tomato and strawberry fruit ripening through the abscisic acid-stress-ripening transcription factor. Plant Biotechnol J 14:2045-2065

Jia H, Wang Y, Sun M, Li B, Han Y, Zhao Y, Li X, Ding N, Li C, Ji W, J W (2013) Sucrose functions as a signal involved in the regulation of strawberry fruit development and ripening. New Phytol 198:453-465

Kafkas E, Koşar M, Paydaş S, Kafkas S, Başer KHC (2007) Quality characteristics of strawberry genotypes at different maturation stages. Food Chem 100:1229-1236

Kallio H, Hakala M, Pelkkikangas AM, Lapveteläinen A (2000) Sugars and acids of strawberry varieties. Eur Food Res Technol 212:81-85

Makinen K, Söderling E (1980) A quantitative study of mannitol, sorbitol, xylitol and xylose in wild berries and commercial fruits. J Food Sci 45:367-371

Linka M, Weber AP (2005) Shuffling ammonia between mitochondria and plastids during photorespiration. Trends Plant Sci 10:461-465

Park JI, Lee YK, Chung WI, Lee IH, Choi JH, Lee WM, Ezura H, Lee SP, Kim IJ (2006) Modification of sugar composition in strawberry fruit by antisense suppression of an ADP-glucose 
pyrophosphorylase. Mol Breed 17:269-279

Pelayo-Zaldivar C, Ebeler S, Kader A (2005) Cultivar and harvest date effects on flavor and other quality attributes of California strawberries. J Food Quality 28:78-97

Ranwala A, Suematsu C, Masuda H (1992) Soluble and wallbound invertases in strawberry fruit. Plant Sci 84:59-64

Reyes FGR, Wrolstad RE, Cornwell CJ (1982) Comparison of enzymatic, gas-liquid chromatographic, and high performance liquid chromatographic methods for determining sugars and organic acids in strawberries at three growth stages of maturity. J Assoc Off Anal Chem 65:126-131

Rolland F, Baena-Gonzalez E, Sheen J (2006) Sugar sensing and signaling in plants: conserved and novel mechanisms. Annu Rev Plant Biol 57:675-709

Ruan YL, Jin Y, Yang YJ, Li GJ, Boyer JS (2010) Sugar input, metabolism, and signaling mediated by invertase: Roles in development, yield potential, and response to drought and heat. Mol Plant 3:942-955

Shanmugam A, Hossain MR, Natarajan S, Jung HJ, Song JY, Kim HT, Nou IS (2017) Sugar content analysis and expression profiling of sugar related genes in contrasting Strawberry (Fragaria $\times$ ananassa $)$ cultivars. J Plant Biotechnol 44:178190
Shanmugavelan P, Kim SY, Kim JB, Kim HW, Cho SM, Kim SN, Kim SY, Cho YS, Kim HR (2013) Evaluation of sugar content and composition in commonly consumed Korean vegetables, fruits, cereals, seed plants, and leaves by HPLC-ELSD. Carbohydr Res 380:112-117

Souleyre E, Iannetta P, Ross H (2004) Starch metabolism in developing strawberry (Fragaria $\mathrm{x}$ ananassa) fruits. Physiol Plantarum 121:369-376

Sturm K, Koron D, Stampar F (2003) The composition of fruit of different strawberry varieties depending on maturity stage. Food Chem 83:417-422

Wang SY, Camp MJ (2000) Temperatures after bloom affect plant growth and fruit quality of strawberry. Sci Hortic-Amsterdam 85:183-199

Wozniak W, Radajewska B, Reszelska-Sieciechowich A, Dejvor I (1997) Sugars and acid content influence organoleptic evaluation of fruits of six strawberry cultivars from controlled cultivation. Acta Hortic 439:333-339

Woodward J (1972) Physicaland chemicalchanges in developing strawberry fruits. J Sci Food Agric 23:465-473

Yu D, Tang H, Zhang Y, Du Z, Yu H, Chen Q (2012) Comparison and improvement of different methods of RNA isolation from Strawberry (Fragria $\times$ ananassa). J Agr Sci-Cambridge 4:51-56 